\title{
VALORES ENERGÉTICOS DO MILHO E DO FARELO DE SOJA DETERMINADOS COM POEDEIRAS NA FASE DE PRODUÇÃO
}

\author{
(Determination of corn and soybean meal energetic values \\ with laying hens in production)
}

\author{
POZZA, P.C.'; ROCHA, L.D. ${ }^{2}$; NUNES, C.G.V.; DEBASTIANI, M. ${ }^{2}$; \\ SCHERER, C. ${ }^{4}$; OELKE, C.A. ${ }^{5}$; OLIVEIRA, A.A.M.A. ${ }^{6}$
}

\begin{abstract}
${ }^{1}$ Professor CCA, UNIOESTE; 'Zootecnista, UNIOESTE; ${ }^{3}$ Medica Veterinária - COPAGRIL, Paraná; ${ }^{4}$ Pós-graduando Zootecnia - UEM; ${ }^{5}$ Mestrando em Produção Animal, Ciências Veterinárias - Universidade Federal do Paraná (UFPR), Curitiba-PR; ${ }^{6}$ Professora CCA, UNIOESTE.
\end{abstract}

\begin{abstract}
RESUMO - O presente trabalho teve pôr objetivo a determinação, em poedeiras em fase de produção, dos valores de energia metabolizável aparente (EMA) e da $\left(E M A_{n}\right)$ corrigida pelo balanço de nitrogênio, do milho e do farelo de soja. Foram utilizadas 84 aves Isabrown com 24 semanas de idade, distribuídas em delineamento experimental de blocos ao acaso, utilizando-se duas rações-referência com 19 e a4\% de PB (Proteína Bruta), respectivamente. No experimento levado a efeito, duas amostras de milho substituíram em $25 \%$ a ração com $19 \%$ de PB e três amostras de farelo de soja substituíram em $15 \%$ a ração com $14 \%$ de $\mathrm{PB}$, tendo sido verificada diferença significativa nos valores energéticos e nos coeficientes de metabolizabilidade das e de amostras de farelo de soja estudadas. Em conclusão, verificou-se que os valores de EMAe EMA ${ }_{n}$ para as três amostras de farelo de soja foram de 2.992, 2.537; 2.248 e de 3.157 e 3.061 ; e 3.590 e $3.477 \mathrm{kcal} / \mathrm{kg}$ de matéria seca, respectivamente, e de 3.157 e 3.061 ; e 3.590 e 3.477 $\mathrm{kcal} / \mathrm{kg}$ de matéria seca para as duas amostras de milho, respectivamente.
\end{abstract}

Palavras-chave: energia metabolizável; milho; farelo de soja; poedeira; produção.

ABSTRACT - The aim of the present research work, carried out with laying hens in the stage of production, was the determination of both apparent metabolic energy (AME) and the nitrogen corrected apparent metabolic energy $\left(\mathrm{AME}_{n}\right)$ of the corn and soybean meals. A total of 84 Isabrown birds aging 24 weaks were alloted in a randomized blocks design, using two basal reference diets containing 19 and $14 \%$ of CP, respectively. For the experiment, two samples of corn replaced in $25 \%$ the reference diet containing $19 \%$ of $\mathrm{CP}$, and three samples of soy bean meal replaced in $15 \%$ the reference ration containing $14 \%$ of $\mathrm{CP}$. It hás been found significant differences in regard to the energetic values and the metabolic coefficients of the reference diets added with soybean meal. In conclusion, it hás been found that the
EMA and $E M A_{n}$ values, expressed as $\mathrm{kcal} / \mathrm{kg}$ as dry matter, for the three samples of soybean meal were 2,292 and 2,537; 2,248 and 1,963; 3,252 and 2,847, respectively, and for the samples of corn, 3,157 and 3,061 and 3,477, respectively

Key-words: metabolizable energy; corn; soybean meal; laying hens; production.

\section{Introdução}

A indústria avícola alcançou desenvolvimento e modernização de forma rápida, atingindo níveis elevados de produtividade nos últimos anos. Atualmente, a produção mundial de ovos gira entorno de 814 bilhões de unidades, destacando-se a China com uma produção de 387 bilhões em 2001, sendo que, o Brasil no mesmo período produziu 15 bilhões de unidades (AVES e OVOS, 2002).

As perspectivas são favoráveis quanto ao aumento no consumo deste alimento, porém, deve-se lembrar sempre que fisiologicamente a ave não consegue mais aumentar o número de ovos produzidos por ciclo de postura, tornando assim a formulação de rações o marco mais importante para diminuir os custos e aumentar eficiência produtiva.

Nesse sentido, busca-se constantemente formular rações economicamente viáveis e eficientes, aumentando-se assim a necessidade de pesquisas relacionadas à composição química e valores de digestibilidade dos nutrientes contidos nos alimentos utilizados nas formulações de rações (NUNES, 2003).

Segundo LIMA (1996), o conhecimento do conteúdo energético dos alimentos é de suma importância para os nutricionistas. Ressaltando-se que aves regulam a ingestão de alimentos de acordo com o conteúdo de energia metabolizável (EM) das dietas, torna-se importante à determinação dos valores de EM dos alimentos utilizados, principalmente do milho e do farelo de soja ROSTAGNO et al. (2000).

Assim sendo, o objetivo desse trabalho foi determinar 
Valores energéticos do milho e do farelo de soja determinados com poedeiras na fase de produção

a composição química, os valores de energia metabolizável e os coeficientes de metabolizabilidade do milho e do farelo de soja, utilizando-se poedeiras semipesadas em produção.

\section{Material e Métodos}

O ensaio biológico para determinação dos valores de energia metabolizável aparente (EMA) e aparente corrigida pelo balanço de nitrogênio $\left(E M A_{n}\right)$ foi realizado em granja comercial no município de Cândido Rondon (PR), no período de outubro a novembro de 2002.

Foram utilizados cinco alimentos, sendo três amostras de farelo de soja e duas amostras de milho de diferentes procedências, os quais substituíram duas rações-referência (TABELA 1), calculadas segundo as exigências propostas por ROSTAGNO et al. (2000), exceto para os níveis de proteína bruta (PB).
Foram realizadas análises laboratoriais segundo as metodologias descritas por SILVA e QUEIROZ (2002) para a determinação da matéria seca (MS), energia bruta (EB), proteína bruta (PB), extrato etéreo (EE), fibra bruta (FB) e matéria mineral (MM) dos alimentos e das rações-referência.

Para a determinação dos valores de EMA e de $\mathrm{EMA}_{n}$, foram utilizadas 84 aves da linhagem Isabrown com 24 semanas de idade, distribuídas em delineamento experimental de blocos ao acaso, com cinco tratamentos (dois milhos e três farelos de soja, as rações referências nesse caso só foram utilizadas para determinar os valores de energia das rações e auxiliar nos cálculos dos valores energéticos dos alimentos), duas rações-referência, dois blocos (a blocagem foi ao tempo, onde não se utilizou o mesmo animal), duas repetições por bloco e três aves por unidade experimental.

TABELA 1 - COMPOSIÇÃO DAS RAÇÕES-REFERÊNCIA, EM PORCENTAGEM NA MATÉRIA NATURAL.

\begin{tabular}{|c|c|c|}
\hline Ingredientes & RR-1 & RR-2 \\
\hline Milho & 52,87 & 69,23 \\
\hline Farelo de Soja & 32,50 & 17,77 \\
\hline Óleo Vegetal & 3,00 & 0,50 \\
\hline Fosfato Bicálcico & 2,14 & 2,11 \\
\hline Calcário & 8,46 & 8,59 \\
\hline DL-Metionina (99\%) & 0,28 & 0,21 \\
\hline L-Lisina.HCl & - & 0,13 \\
\hline L-Triptofano & - & 0,02 \\
\hline Sal comum & 0,53 & 0,55 \\
\hline Cloreto de Colina (60\%) & 0,02 & 0,02 \\
\hline Mistura vitamínica & 0,12 & 0,12 \\
\hline Mistura mineral $^{2}$ & 0,07 & 0,07 \\
\hline Antioxidante & 0,01 & 0,01 \\
\hline Inerte & & 0,67 \\
\hline TOTAL & 100,00 & 100,00 \\
\hline \multicolumn{3}{|l|}{ Composições calculadas } \\
\hline Energia Metabolizável (kcal/kg) & 2.800 & 2.800 \\
\hline Proteína Bruta (\%) & 19,00 & 14,00 \\
\hline Lisina digestível (\%) & 0,93 & 0,72 \\
\hline Metionina digestível (\%) & 0,55 & 0,42 \\
\hline Metionina + Cistina digestível (\%) & 0,81 & 0,63 \\
\hline Treonina digestível (\%) & 0,66 & 0,47 \\
\hline Triptofano digestível (\%) & 0,22 & 0,16 \\
\hline $\mathrm{Ca}(\%)$ & 3,90 & 3,90 \\
\hline P disponível (\%) & 0,50 & 0,50 \\
\hline $\mathrm{Na}(\%)$ & 0,25 & 0,25 \\
\hline
\end{tabular}

${ }^{1}$ Conteúdo/kg: Vit. A, 10.000.000 Ul; Vit. D, 2.200.000 Ul; Vit. E, 6.000 Ul; Vit. K, 1,4 g; Vit. B, 1,4 g; Vit. B ${ }_{2}$, 4,0 g; Vit. $\mathrm{B}_{6}, 1,8 \mathrm{~g}$; Vit. $\mathrm{B}_{12}, 15.000 \mathrm{mcg}$; Ac. Nicotínico, 25,0 g; Ác. Fólico 0,4 g; Ác. pantotênico, 8,5 g; Se, 0,3 g; ${ }^{2}$ Conteúdo/kg: $\mathrm{Mn}, 150 \mathrm{~g} ; \mathrm{Zn}, 100 \mathrm{~g}$; Fe, $100 \mathrm{~g}$; Cu, $16 \mathrm{~g} ; \mathrm{I}, 1,5 \mathrm{~g} ;{ }^{3} \mathrm{BHT} ;{ }^{4}$ Areia lavada.

A utilização de duas rações-referência teve a finalidade de fornecer o nível de proteína bruta (PB) mais próximo das exigências das aves, evitando-se assim, um desperdício de energia no metabolismo protéico. Dessa forma, duas amostras de milho substituíram em $25 \%$ a ração-referência com $19 \%$ de proteína bruta (PB) e três amostras de farelo de soja substituíram em $15 \%$ a ração-referência com $14 \%$ de PB.

As aves foram alojadas em gaiolas metálicas, distribuídas lateralmente em um galpão convencional para galinhas poedeiras. Foram utilizados bebedouro 
tipo calha de PVC, com água corrente percorrendo toda a extensão frontal da gaiola e comedouro tipo calha de madeira, disposto sob o bebedouro, sendo fornecidos água e ração experimental à vontade.

O experimento teve duração de 10 dias, sendo cinco dias para adaptação das aves às rações experimentais e os outros cinco dias para coleta total de excreta, as quais foram realizadas duas vezes ao dia, as 8 e às 17 horas, evitando-se assim, uma possível fermentação das mesmas. Para tal, foram utilizadas bandejas metálicas cobertas com plástico, sob as gaiolas de cada unidade experimental.

As excretas foram acondicionadas em sacos plásticos, devidamente identificadas e armazenadas em freezer após cada coleta, sendo que, ao final da fase de coleta, estas foram descongeladas, quantificadas, homogeneizadas e retiradas amostras para realização das análises de matéria seca (MS), de nitrogênio (N) e de energia bruta (EB), segundo as metodologias descritas por SILVA e QUEIROZ (2002).

Uma vez obtidos os resultados das análises laboratoriais dos alimentos, das rações-referência e das excretas, foram calculados os valores de energia metabolizável aparente (EMA) e aparente corrigida pelo balanço de nitrogênio $\left(\mathrm{EMA}_{\mathrm{n}}\right.$ ), por meio de equações propostas por MATTERSON et al. (1965). Com base nos valores de energia bruta e de energia metabolizável dos alimentos, foram calculados os coeficientes de metabolizabilidade dos valores energéticos, segundo LEESON e SUMMERS (2001).

Como procedimento estatístico, foi aplicado o teste de comparação de médias Student Newman Keuls (SNK), ao nível de $5 \%$ de probabilidade entre as médias dos valores de energia metabolizável e entre os valores médios dos coeficientes de metabolizabilidade para as amostras de farelo de soja; além disso utilizou-se o teste $F$ entre as médias dos valores energéticos e nos coeficientes de metabolizabilidade para as amostras de milho, as quais foram realizadas por meio do programa SAEG - Sistema para Análises Estatísticas e Genéticas (Universidade Federal de Viçosa - UFV, 1999).

\section{Resultados e Discussão}

Composição Química: Os valores de composição química e de energia bruta dos alimentos estão apresentados na TABELA 2.

TABELA 2 -COMPOSIÇÃO QUÍMICA E VALORES DE ENERGIA BRUTA DOS ALIMENTOS, NA MATÉRIA NATURAL.

\begin{tabular}{lcccccc}
\hline Alimentos & MS\% & EB $(\mathrm{kcal} / \mathrm{Kg})$ & PB\% & EE\% & MM\% & FB\% \\
\hline Farelo de Soja 1 & 93,82 & 4.100 & 46,95 & 1,06 & 6,53 & 3,98 \\
Farelo de Soja 2 & 93,97 & 4.024 & 47,08 & 2,52 & 6,18 & 3,68 \\
Farelo de Soja 3 & 93,92 & 4.101 & 48,39 & 2,12 & 6,21 & 2,66 \\
\hline Milho 1 & 88,51 & 3.704 & 9,13 & 3,46 & 1,67 & 0,44 \\
Milho 2 & 93,26 & 3.886 & 8,83 & 3,10 & 1,42 & 0,60 \\
\hline
\end{tabular}

Houve variação na composição química entre os alimentos. Segundo ALBINO e SILVA (1996), essas variações podem ser causadas por vários fatores, como solo, clima e tipos de processamento que sofrem os alimentos e que, estes fatores podem ocasionar alterações na composição química dos alimentos, principalmente nos teores de minerais e proteína bruta.

Os valores de proteína bruta e matéria mineral dos milhos foram superiores aos valores citados por ROSTAGNO et al. (2005), porém os valores de gordura e fibra bruta foram inferiores aos citados por esses autores.

Os valores referentes ao farelos de soja apresentaram valores de proteína bruta variando de 46,95 a 48,39\%, valores esses semelhantes aos citados por ROSTAGNO et al. (2005) para o farelo de soja com $48 \%$ de proteína bruta. Os valores de matéria mineral e fibra bruta dos farelos de soja foram inferiores aos citados por ROSTAGNO et al. (2005) e RODRIGUES et al. (2002). Para os valores de gordura, os farelos de soja 2 e 3 apresentaram valores semelhantes aos citados por RODRIGUES et al. (2002).

Valores de energia metabolizável aparente e energia metabolizável aparente corrigida pelo balanço de nitrogênio: Os valores de energia metabolizável aparente (EMA), e aparente corrigida pelo balanço de nitrogênio $\left(E M A_{n}\right)$, expressos em $\mathrm{kcal} / \mathrm{kg}$ de matéria seca (MS), e seus respectivos coeficientes de variação estão apresentados na TABELA 3. Entre os farelos de soja, houve diferença significativa $(P<0,05)$ entre os valores de EMA e $E A_{n}$, o que não aconteceu para as duas amostras de milho. As variações encontradas entre os farelos de soja, provavelmente se devem às variações encontradas em suas composições químicas. 
Valores energéticos do milho e do farelo de soja determinados com poedeiras na fase de produção

TABELA 3 - VALORES DE ENERGIA METABOLIZÁVEL APARENTE (EMA), APARENTE CORRIGIDA $\left(\text { EMA }_{N}\right)^{1}$ E SEUS RESPECTIVOS COEFICIENTES DE VARIAÇÃO(CV).

\begin{tabular}{lcc}
\hline Alimentos & EMA $(\mathrm{kcal} / \mathrm{kg})$ & $\mathrm{EMA}_{\mathrm{n}}(\mathrm{kcal} / \mathrm{kg})$ \\
\hline Farelo de Soja 1 & $2.992^{\mathrm{A}^{*}}$ & $2.537^{\mathrm{A}^{*}}$ \\
Farelo de Soja 2 & $2.248^{\mathrm{B}^{*}}$ & $1.963^{\mathrm{B}^{*}}$ \\
Farelo de Soja 3 & $3.252^{\mathrm{A}^{*}}$ & $2.847^{\mathrm{A}^{*}}$ \\
\hline CV (\%) & 8,34 & 9,18 \\
\hline Milho 1 & 3.157 & 3.061 \\
Milho 2 & 3.590 & 3.477 \\
\hline CV (\%) & 7,64 & 7,07 \\
\hline
\end{tabular}

${ }^{1}$ Valores expressos em $\mathrm{kcal} / \mathrm{kg}$ de matéria natural.

*Médias seguidas pela mesma letra, na coluna, não diferem entre si pelo Teste de SNK, ao nível de 5\%.

Os valores das amostras de farelo de soja variaram de 2.248 a $3.252 \mathrm{kcal} / \mathrm{kg}$ na MS, e 1.963 a $2.847 \mathrm{kcal} /$

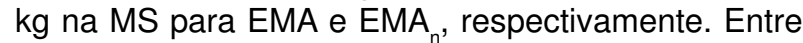
as amostras de milho, os valores de EMA e EMA, expressos em $\mathrm{kcal} / \mathrm{kg}$ de MS, foram de 3.157 e 3.590 , e de 3.061 e 3.477 , respectivamente.

Os valores de EMA das amostras de farelo de soja foram em média $15,6 \%$ superiores aos de EMA , e o valor médio de EMA das amostras de milho foram 3,2\% superiores que $E M A_{n}$. Isto mostra que, as aves tendem a reter o nitrogênio, principalmente, quando o alimento que está sendo fornecido é considerado protéico.

O valor de EMA $A_{n}$ do farelo de soja 1 foi 4,10 e $12 \%$ superior aos valores propostos pelo NRC (1994), MAA (2000) e JANSSEN (1989), respectivamente, e semelhante aos valores propostos por LEESON e SUMMERS (2001) e ROSTAGNO et al. (2005). O farelo de soja 2 foi inferior em 24 e $29 \%$ aos valores propostos pelo NRC (1994) e ROSTAGNO et al. (2005), respectivamente. Para a amostra de farelo de soja 3 os valores inferiores quando comparados aos citados por JANSSEN (1989), MAA (2000) e ROSTAGNO et al. (2000), entretanto este é superior ao citado por ROSTAGNO et al. (2005). RODRIGUES et al. (2002) estudando 4 diferentes farelos de soja, determinaram valores que variaram de 2.337 a $2.607 \mathrm{kcal} / \mathrm{kg}$, entretanto esses valores foram obtidos com frangos em crescimento e galos adultos.

Observando-se o valor de EMA ${ }_{n}$ para a amostra de milho 1 , constatou-se que o mesmo foi inferior quando comparado com a literatura nacional e estrangeira. $O$ valor de $E M A_{n}$ da amostra de milho 2 foi inferior ao valor citado por JANSSEN (1989) e ROSTAGNO et al. (2005) e superior aos valores encontrados pela EMBRAPA (1991) e NRC (1994).

Esses valores de energia metabolizável corrigidos pelo balanço de nitrogênio, se fazem necessários, pois em um ensaio de metabolismo, é impossível assegurar que todas as aves apresentem a mesma taxa de crescimento. Quanto às diferenças nos valores de EM, as mesmas podem estar ligadas a diversos fatores, como processamento, composição química do alimento, relação entre os nutrientes e segundo VIEITES (1999) a idade das aves e aos níveis de inclusão do alimento a ser testado.

Coeficiente de metabolizabilidade da energia bruta: $\mathrm{Na}$ TABELA 4, estão apresentados os valores dos coeficientes de metabolizabilidade aparente (CMA) e aparente corrigida $\left(\mathrm{CMA}_{\mathrm{n}}\right)$ dos alimentos estudados.

TABELA 4 - COEFICIENTES DE METABOLIZABILIDADE APARENTE (CMA) E APARENTE CORRIGIDA (CMA ${ }_{N}$ NA MATÉRIA NATURAL.

\begin{tabular}{lcc}
\hline Alimentos & $\mathrm{CMA}(\%)$ & $\mathrm{CMA}_{\mathrm{n}}(\%)$ \\
\hline Farelo de Soja 1 & $68,47^{\mathrm{A}^{*}}$ & $58,06^{\mathrm{A}^{*}}$ \\
Farelo de Soja 2 & $52,51^{\mathrm{B}^{*}}$ & $45,86^{\mathrm{B}^{*}}$ \\
Farelo de Soja 3 & $74,46^{\mathrm{A}^{*}}$ & $65,19^{\mathrm{A}^{*}}$ \\
\hline CV (\%) & 8,36 & 9,20 \\
\hline Milho 1 & 85,23 & 82,63 \\
Milho 2 & 92,38 & 89,48 \\
\hline CV (\%) & 7,53 & 6,95
\end{tabular}

*Médias seguidas pela mesma letra, na coluna, não diferem entre si pelo Teste de SNK, ao nível de $5 \%$. 
Houve diferença significativa $(P<0,05)$ entre os coeficientes de metabolizabilidade das amostras de farelo de soja estudadas, essas variaram de 45,86 a $74,46 \%$. As amostras de milho apresentaram em média um aproveitamento de $88,81 \%$ da energia bruta como energia metabolizável, enquanto que as amostras de farelo de soja apresentaram um aproveitamento de $65,15 \%$. Esses resultados foram semelhantes para o aproveitamento da energia bruta como energia metabolizável aparente corrigida pelo balanço de nitrogênio onde as amostras de milho apresentaram um aproveitamento de 86,06 e as amostras de farelo de soja apenas $56,37 \%$. Esse aspecto pode ser em função da maior quantidade de fibra bruta presente no farelo de soja em relação ao do milho, pois segundo PENZ JR. et al. (1999), o alto teor de fibra bruta presente nos alimentos, tende a provocar uma diminuição no consumo de ração pelas aves, ocorrendo uma diminuição na estimativa dos valores energéticos.

Quando comparados com NUNES (2003), os valores de $\mathrm{CMA}_{n}$ do farelo de soja 1 e 3 foram superiores, entretanto para o farelo de soja 2 este foi inferior ao valor citado pelo autor supracitado. Observou-se também que, o valor de $\mathrm{CMA}_{n}$ da amostra de milho 1 foi inferior aos valores encontrados por NUNES (2003). Já o valor de $\mathrm{CMA}_{\mathrm{n}}$ do milho 2 foi superior ao valor do autor supracitado.

Segundo NUNES (2003), grandes variações nos coeficientes de metabolizabilidade dos alimentos podem ser explicados pelo fato dos alimentos sofrerem processamentos diferentes, resultando em matériasprimas de diferentes qualidades. Muitos desses processamentos visam inativar os fatores antinutricionais porém, quando estes métodos são utilizados em excesso ou insuficientemente, diminuem a digestibilidade e a disponibilidade de alguns nutrientes para as aves (PENZ Jr. 2001).

\section{Conclusões}

De acordo com os resultados obtidos, conclui-se que

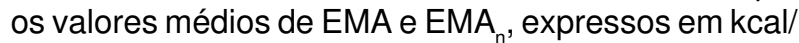
$\mathrm{kg}$ de MS, foram de 2.831 e 2.449 para as amostras de farelo de soja e para as amostras de milho foram de 3.374 e 3.269 , respectivamente. Os coeficientes médios de metabolizabilidade aparente (CMA) e aparente corrigida $\left(\mathrm{CMA}_{\mathrm{n}}\right)$ para as amostras de farelo de soja foram de 65,15 e $56,37 \%$ e para as amostras de milho foram de 88,81 e $86,06 \%$, respectivamente.

\section{Referências}

ALBINO, L.F.T.; SILVA, M.A. Valores nutritivos de alimentos para aves e suínos determinados no Brasil. In: SIMPÓSIO INTERNACIONAL SOBRE EXIGÊNCIAS NUTRICIONAIS DE AVES E SUÍNOS. 1996, Viçosa. Anais... Viçosa: UFV, 1996, p. 303-318.

AVES E OVOS. Anualpec 2002. FNP Consultoria e Agro Informativos. São Paulo - SP, ano 2002, p.269-279.
Empresa Brasileira de Pesquisa Agropecuária. Centro Nacional de Pesquisa de Suínos e Aves (CNPSA) EMBRAPA-CNPSA. Tabela de composição química e valores energéticos de alimentos para suínos e aves. $3^{\underline{a}}$ ed., Concórdia-SC, EMBRAPA-CNPSA, 1991.

JANSSEN, W.M.M.A. European table of energy values for poultry feedstuffs, $3^{\text {rd }}$ Edition, 1989.

LEESON, S.; SUMMERS, J.D. Scott's Nutrition of the Chicken. 4.ed., 2001.

LIMA, I.L. Níveis nutricionais utilizados nas rações pela indústria avícola. In: SIMPÓSIO INTERNACIONAL SOBRE EXIGÊNCIAS NUTRICIONAIS DE AVES E SUÍNOS. 1996, Viçosa. Anais... Viçosa: UFV, 1996. p.389-402.

MATTERSON, L.D.; POTTER, L.M.; STUTZ, M.W.; SINGSEN, E.P. The metabolizable energy of feed ingredients for chickens. University of Connecticut Storrs. Agricultural Experiment Station Research Report, v.11, $11 \mathrm{p}, 1965$.

MINISTÉRIO DA AGRICULTURA E DO ABASTECIMENTO - MAA. Normas e padrões de Nutrição e Alimentação Animal. Revisão, 2000.

NATIONAL RESEARCH COUNCIL - NRC. Committe on Animal Nutrition. Subcommitte on Poultry Nutrition. Washington, EUA. Nutrient Requirements of Poultry, 9.ed. Washington, National Academy os Sciences, 1994. $155 p$.

NUNES, R.V. Digestibilidade de nutrientes e valores energéticos de alguns alimentos para aves. Viçosa, 2003. Tese (Doutorado em Zootecnia) - Universidade Federal de Viçosa, Viçosa, 2003.

PENZ JR., A.M. Soja e seus derivados na alimentação de aves. In: SIMPÓSIO SOBRE INGREDIENTES NA ALIMENTACAO ANIMAL. 2001, Campinas. Anais... Campinas: CBNA-SP, 2001, p. 354.

RODRIGUES, P.B.; ROSTAGNO, H.S.; ALBINO, L.F.T.; et al. Valores energéticos da soja e subprodutos da soja, determinados com frangos de corte e galos adultos. Revista Brasileira de Zootecnia, v.31, n.4, p.171-1782, 2002.

ROSTAGNO, H.S.; ALBINO, L.F.T.; DONZELE, J.L.; GOMES, P.C.; FERREIRA, A.S.; OLIVEIRA, R.F.; LOPES, D.C. Tabelas brasileiras para aves e suínos. Composição de alimentos e exigências nutricionais. 141p. Viçosa: UFV. 2000.

ROSTAGNO, H.S.; ALBINO, L.F.T.; DONZELE, J.L.; GOMES, P.C.; OLIVEIRA, R.F.; LOPES, D.C.; FERREIRA, A.S.; BARRETO, S.L.T. Tabelas brasileiras para aves e suínos. Composição de alimentos e exigências nutricionais. 186p. Viçosa: UFV. 2005.

SILVA, D.J., QUEIROZ, A.C. Análises de alimentos: métodos químicos e biológicos. Viçosa: UFV. 2002. 
Valores energéticos do milho e do farelo de soja determinados com poedeiras na fase de produção

UNIVERSIDADE FEDERAL DE VIÇOSA - UFV. Manual de utilização do programa SAEG (Sistema para Análise Estatísticas e Genéticas). Viçosa: Imprensa Universitária, 1999.
VIEITES, F.M. Valores energéticos e de aminoácidos digestíveis de farinhas de carne e ossos para aves. Viçosa, 1999. Dissertação (Mestrado em Zootecnia) Universidade Federal de Viçosa, Viçosa, 1999.

Recebido para publicação:

$08 / 05 / 2006$

Aprovado:

$09 / 08 / 2006$ 